\title{
Creation of Entrustable Professional Activities (EPAs) in obstetrics and gynecology for medical undergraduate students
}

\section{Elaboração de Atividades Profissionais Confiáveis (APCS) em ginecologia e obstetrícia para a graduação médica}

Andrea Mora De Marco Novellino' ${ }^{1}$ (1) andreanovellino@hotmail.com Izabel Cristina Meister Martins Coelho' (1) $\mid$ izamcoelho@gmail.com

\begin{abstract}
Introduction: This article features "Entrustable Professional Activities (EPAs)" in the Obstetrics and Gynecology field designed for medical undergraduates, aiming to support the teaching/learning process.

Objective: The aim is for the graduate to be competent to meet the minimum requirements necessary for the student in this field.

Method: In this study, EPAs were created based on an international template already in use and validated using the Delphi technique. The structuring of the EPAs was based on the international literature: "Core Entrustable Professional Activities for Entering Residency: Curriculum Developer's Guide" from the Association of American Medical Colleges (AAMC). The content for the topics of each EPA was based on the publication "The Obstetrics and Gynecology Milestone Project" from the joint action of the Accreditation Council for Graduate Medical Education (ACGME), the American College of Obstetrics and Gynecology (ACOG) and the American Board of Obstetrics and Gynecology (ABOG).

Results: Thirteen EPAs were created with topics for teaching in that field during undergraduate school. A checklist was created for each EPA, aiming to guide the evaluator and the student regarding the performance of the tasks defined in the EPAs.

Conclusion: The EPAs with checklists bring an innovative proposal for Obstetrics and Gynecology teaching in medical graduation since they facilitate and operationalize the learning, the development, and the observation of the acquisition of knowledge, skills and attitudes required for the performance of each topic in the area, thus helping the training of a competent professional. At the end of the medical course, the ability to perform all EPAs identifies a competent graduate in Gynecology and Obstetrics regarding the general practitioner.
\end{abstract}

Keywords: Entrustable Professional Activities; Medical Education; Clinical Competence.

\section{RESUMO}

Introdução: Este artigo traz "Atividades Profissionais Confiáveis" (APCs) na área de ginecologia e obstetrícia elaboradas para a graduação médica a fim de sustentar o processo de ensino-aprendizagem.

Objetivo: O objetivo é que o egresso seja competente para atender aos requisitos mínimos necessários ao estudante nesta área.

Método: Neste estudo, as APCs foram criadas com base num molde internacional já utilizado e validadas pela técnica Delphi. A estruturação das APCs foi baseada na literatura internacional: "Principais atividades profissionais confiáveis (APCs) para acesso à Residência Médica: Guia para Elaboradores de Currículos" da Associação Americana de Faculdades Médicas (AAMC). O conteúdo dos temas para elaboração de cada APC foi baseado na publicação "Pilares da Obstetrícia e Ginecologia" oriundo da ação conjunta do Conselho de Acreditação de Educação Médica na Graduação (ACGME), Colégio Americano de Ginecologia e Obstetrícia (ACOG) e pelo Conselho Americano de Ginecologia e Obstetrícia (ABOG).

Resultados: Foram elaboradas treze APCs com temas para o ensino da referida área durante a graduação. Para cada APC, uma lista de verificação foi elaborada de forma a orientar o avaliador e o estudante quanto à execução das tarefas definidas nas APCs.

Conclusão: As APCs com as listas de verificação trazem uma proposta inovadora no ensino da ginecologia e obstetrícia na graduação médica, uma vez que facilitam e operacionalizam o aprendizado, o desenvolvimento e a observação da aquisição dos conhecimentos, habilidades e atitudes exigidos na execução de cada tema na área, auxiliando, assim, a formação de um profissional competente. Ao final do curso de medicina, a capacidade de realização de todas as APCs identifica um egresso competente em ginecologia e obstetrícia naquilo que concerne ao médico generalista.

Palavras-chave: Atividades Profissionais Confiáveis; Educação Médica; Competência Clínica.

${ }^{1}$ Faculdades Pequeno Príncipe, Curitiba, Paraná, Brazil.

Chief Editor: Rosiane Viana Zuza Diniz.

Associate Editor: Pedro Tadao Hamamoto Filho.

Received on 10/11/20; Accepted on 07/30/21.

Evaluated by double blind review process. 


\section{INTRODUCTION}

The need to take responsibility for the health of the population and the protection of citizens against incompetent medical professional practice led to the concept of competence and the identification of the medical curriculum components ${ }^{1}$. By refocusing on professional practice, schools are required to rethink their curricula and evaluation processes, reorienting educational planning based on the desirable competence profile for their graduates ${ }^{2}$. More difficult to assess but fundamental qualities such as ethics, professionalism, communication and leadership should also be sought and evaluated during professional development. It is not enough to acquire knowledge and skills ${ }^{3}$; it is necessary to develop actions to achieve the final goals, applying the knowledge and skills that have been acquired.

For a medical education to be comprehensive and integrative, it is necessary to define the expected competences of the professional one wants to train and to verify whether these competences have been achieved at the end of medical graduation. But how do you know whether the student has really developed them at graduation? In this context, we present the Entrustable Professional Activities (EPAs) in gynecology and obstetrics with their respective checklists to assist the teachinglearning process and the assessment of the competences acquired during medical graduation.

The EPAs are professional practice units defined as tasks or responsibilities that medical students in training have to carry out without direct supervision once they have sufficiently achieved a specific competence. The EPAs are practicable, observable and measurable in their processes and results and, therefore, appropriate for reliable decision-making. EPAs are a means of translating competences into clinical practice. Competences are physicians' descriptors, EPAs are work descriptors ${ }^{4}$.

The concept was developed to operationalize competence-based education in postgraduate medical education, in the medical residency model ${ }^{5,6}$, but it is now widely applied in the education of health professionals ${ }^{7,8}$. From this perspective, a project that aligns the goals that must be achieved at the end of graduation with what is expected of the graduate on the first day of medical residency - or work in the job market - can contribute to the full training of physicians.

The EPAs operate as essential professional activities that must be entrusted to a professional to be carried out. Each EPA is a synthesis of several competence domains (for instance, medical knowledge, communication skills and professionalism) and requires the integration of knowledge, skills and attitudes ${ }^{9}$. The EPAs are professional practice units that constitute the daily practice of clinicians ${ }^{1,5}$. They constitute a list of tasks to be performed in a certain period of time during patient care.
The question whether the student in the health area has acquired competence for the profession at the end of the course is the role of each teacher, who is responsible for acquiring a longitudinal view of the teaching objectives and managing the progression of students's learning ${ }^{10}$.

EPAs and competences are not mutually exclusive. On the contrary, EPAs require competence integration, and competences are best assessed in the context of performance, practice, as it can be provided by the structure of an EPA ${ }^{11}$.

In this sense, tools capable of visualizing the strengths in the academic training process are required, as well as providing interventions in the weaknesses, aiming at the training of competent physicians in the health area, with emphasis on primary health care. The performance of the EPA by the student under supervision allows observing the weak points during medical training, correcting these points before entering the medical residency or the job market, and providing the student with a view of what needs to be improved in their learning.

This is an innovative proposal for the teaching of Gynecology and Obstetrics during medical undergraduate school, whose main objective is to help the student to achieve the desired competence in the area, and as a secondary objective, to help the teacher to evaluate the student regarding the acquisition of a certain competence.

\section{METHOD}

This study was approved by the Research Ethics Committee under Opinion number 2.786.783.

The method used when preparing the EPAs is internationally accepted. It is an initial proposal based on international models that served as guiding references in the creation of the EPAs: the "Core Entrustable Professional Activities (EPAs) for Entering Residency: Curriculum Developer's Guide"11 and the joint work developed by the Accreditation Council for Graduate Medical Education (ACGME), the American College of Obstetrics and Gynecology (ACOG) and the American Board of Obstetrics and Gynecology (ABOG), entitled "The Obstetrics and Gynecology Milestone Project"12.

For each EPA, a checklist was drawn up to assess task progression. The checklist was based on the description of the activity tasks that the student must execute during the performance of the correlated EPA. Thirteen EPAs and thirteen checklists corresponding to each of the EPAs were created.

This proposal went through a content validation process called the Delphi technique, which took place entirely online during an estimated period of four months for data collection and involved experts in the area. Thirty-two experts from public and private Higher Education Institutions were selected. The eligibility criteria for the inclusion of 
experts were: being a physician specialized in gynecology and obstetrics and a university professor in this same area in the medical undergraduate course. The time that each one had worked as an expert and teacher varied between six and twelve years. They were approached individually via email and invited to answer a questionnaire evaluating the EPAs, together with their respective checklists, and to issue suggestions on the content.

The questionnaire used for the assessment of experts was created as follows: in the first round, the thirteen EPAs created together with their corresponding checklists were presented. For each EPA, four questions were asked, as described below:

- Is the EPA clearly, unambiguously and objectively described, allowing the teacher to easily identify what should be performed?

- Is the EPA relevant to the teaching Obstetrics and Gynecology in undergraduate school?

- Is the EPA pertinent to the teaching Obstetrics and Gynecology in undergraduate school?

The answers' agreement was evaluated according to the answers in a Likert scale for each question, graded from 1 (totally disagree) to 5 (totally agree). Finally, the fourth openended question was asked in a text, which the expert could or could not answer according to their assessment of the EPA:

- Based on your experience, would you like to add any suggestions, comments or changes to the text?

Each checklist was presented in the questionnaire just below its respective EPA and exactly the same four questions were asked.

Twenty answers returned in the first round. The proposed EPAs were praised for their design and content, which was assessed for clarity, relevance and pertinence. There was $100 \%$ agreement on relevance and pertinence, and $85 \%$ on clarity. In this item, some suggestions were submitted in writing, such as: "change the order of items" and "small change in the title", which were accepted and modified in the text. Another suggestion was the creation of a topic for the construction of more EPAs, which in this specific case, was not included in this work, as the suggestion was not appropriate for undergraduate teaching, as it was a topic that concerns the specialist in gynecology and obstetrics during medical residency, therefore not fitting the proposal in question that aims at the use of EPA in undergraduate school. Therefore, after incorporating the suggestions, a second round was carried out among the 20 respondents, from whom we received 18 answers with the agreement of all involved. Table 1 shows the participation of respondents in each round.
The EPA's content validation indicates whether it is really part of the daily work according to its definition and whether it is appropriate for its purpose. The validation of a group of EPAs is also intended to cover the activities of a profession. This can be done with the experts' opinion. The expert's judgment not only ensures the quality of the group of EPAs, but also informs and engages teachers, who will be able to work with these EPAs in the future ${ }^{13}$ (Figure 1).

\section{Preparation of EPAs}

Thirteen EPAs were built for the teaching of gynecology and obstetrics in medical graduation based on the Core Entrustable Professional Activities for Entering Residency: Curriculum Developer's Guide ${ }^{11}$, and on the Milestones Project ${ }^{12}$ arising from the joint action of the Accreditation Council for Graduate Medical Education (ACGME), the American College of Obstetrics and Gynecology (ACOG) and the American Board of Obstetrics and Gynecology (ABOG).

Table 1. Participants in each round and duration.

\begin{tabular}{cccc}
\hline Rounds & Duration & $\begin{array}{c}\text { Participants } \\
\text { (Received } \\
\text { questionnaire) }\end{array}$ & $\begin{array}{c}\text { Participants } \\
\text { (Respondents) }\end{array}$ \\
\hline 1st Round & 63 days & 32 & 20 \\
2nd Round & 50 days & 20 & 18 \\
\hline
\end{tabular}

Figure 1. Steps involved in the preparation and validation of EPAs.

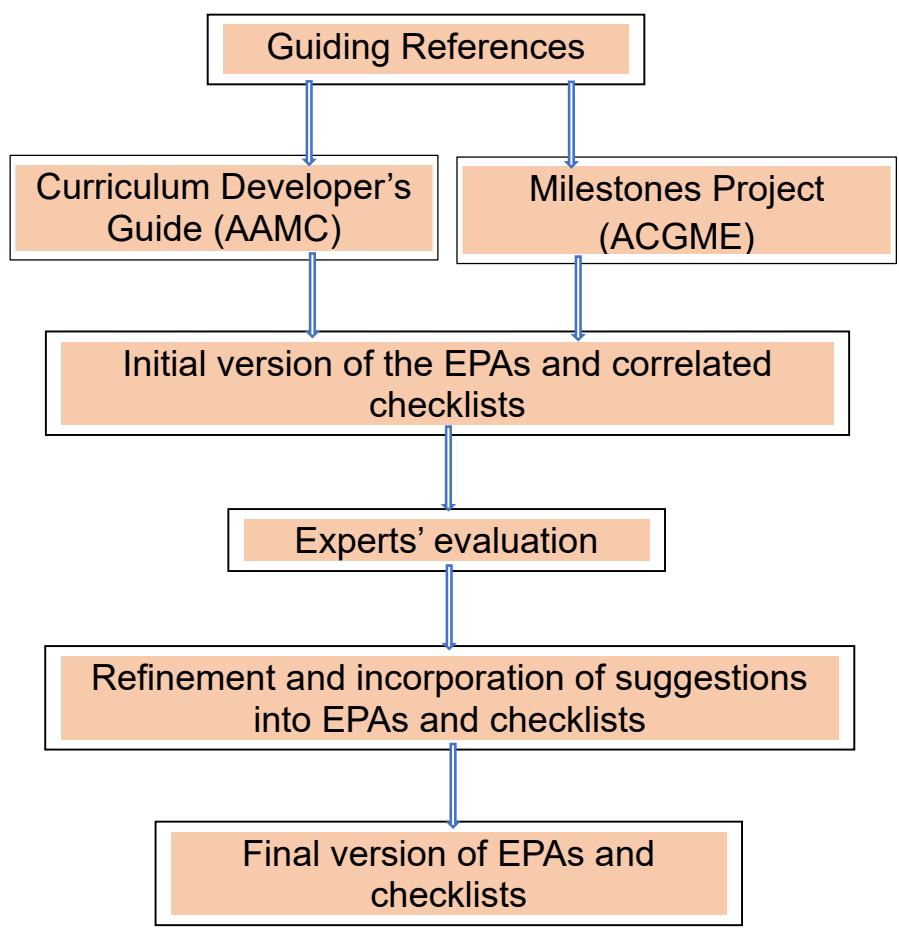


The Milestones were designed to be used in the evaluation of resident physicians during their participation in medical residency programs. They provide a framework for assessing the resident physician's development regarding key attributes of the medical competence elements in a specialty or subspecialty. However, it was used here in the idealistic sense of what is expected of the graduate on their first day after graduation, correlating to level 1 of the Milestones. The Milestones are organized into numbered levels and going from level 1 to level 5 is synonymous with going from beginner to expert.

The initial idea of this study was to adapt the already existing EPAs internationally in the $\mathrm{AAMC}^{11}$ material to be use in the teaching of gynecology and obstetrics in undergraduate courses. However, this was a limitation, since it would not include several practices that are typical of the specialty. Therefore, we chose to create specific EPAs with topics in gynecology and obstetrics.

The EPAs consider the functions that the students should ideally perform on a given topic until they can perform the task without direct supervision at the end of undergraduate school. The structure of each EPA has a header with the title of the topic that is covered in the EPA, with space to include the name of the student, of the evaluator and the date of that EPA. The student can repeat the EPA performance on different dates throughout the course, with the same or another evaluator, and thus be able to analyze their progress in the activity performance. The structure of each EPA also includes: a description of the activity to be carried out with an indication of what knowledge the student must previously have; their roles in this activity, indicating the competences they must develop and perform when carrying out the EPA; the competence domains that are relevant to this activity; and the place for the evaluator to annotate how the student must act when performing that EPA in relation to direct or indirect supervision. The relevant competence domains in the development of each EPA are described in each activity as "Relevant Competence Domains in this activity" and were taken from the Core Entrusted Professional Activities (EPAs) for Entering Medical Residency: Curriculum Developer's Guide ${ }^{11}$.

In the model suggested by the American Association of Medical Colleges (AAMC), which created the general EPAs, there is no checklist associated with each EPA, and its creation is one of the objectives of this research.

Once all the items on the checklist have been fulfilled or not, the evaluator will be able to consider how the student can work during the performance of the task proposed by that EPA, described as follows:

- "Should work only under direct supervision"

- "Can work under indirect or remote supervision"
- "Can work without supervision" - this item identifies the achieved competence; however, working without supervision is not carried out at undergraduate school for legal reasons.

The student aims to perform the tasks described in the EPA to reach the relevant domains and develop the specific skills required for that activity until they reach the level "Can work without supervision", which is expected for the medical course graduate. To visualize the student's progress when performing the proposed activity in the EPA, the evaluator ticks one of the options in the field "Progression in this EPA".

To prepare the content in gynecology and obstetrics of each EPA, the subjects were adapted from what is stated in level 1 of each topic of the Milestone Project. This level 1 was considered the "milestone" to be reached by the student. At this point, the evaluator can consider the student to be capable or "reliable" to perform a certain task.

\section{RESULTS}

The topics of the thirteen created EPAs were:

EPA 1: Carry out the anamnesis (focusing on Obstetrics and Gynecology).

EPA 2: Perform the physical examination of the nonpregnant woman (Gynecological).

EPA 3: Perform the physical examination of the pregnant woman (Obstetrics).

EPA 4: Patient care during the intrapartum period.

EPA 5: Perform the physical examination of the puerperal woman.

EPA 6: Perform the Pap smear collection.

EPA 7: Interpret common diagnostic and screening laboratory and imaging tests in Obstetrics and Gynecology.

EPA 8: Establish a differential diagnosis and diagnostic hypothesis.

EPA 9: Principles of gynecological surgery and perioperative care.

EPA 10: Approach to abdominal/pelvic pain (acute and chronic) and pelvic mass.

EPA 11: Approach to abnormal uterine bleeding (acute and chronic).

EPA 12: Approach to First Trimester Bleeding.

EPA 13: Family Planning and Infertile Couple Investigation.

The objective of each EPA is for the students to develop the skills necessary to perform a certain task that is part of their daily professional routine in gynecology and obstetrics and to be able to perform it after medical graduation. The objectives to be achieved in each EPA are clear in the checklist that evaluates 
whether the student was able to perform the proposed tasks that will culminate in the full achievement of the EPA and, consequently, is considered able to perform what was proposed.

Below are three examples of the EPAs proposed in gynecology and obstetrics with their respective checklists $(\mathrm{CH})$, which can be partially applied from the beginning of the course and reapplied with greater complexity until the end of the course and in graduates (Frames 1, 2 and 3):

Frame 1. EPA 3 - PERFORMING THE PHYSICAL EXAMINATION OF THE PREGNANT WOMAN (Obstetrics).

\section{EPA 3} Student:

Evaluator:

The student must be able to perform a complete physical examination without supervision in an organized and sequential manner, respecting the patient. The physical examination must

Activity description be adapted to the clinical situation (pregnant woman) and the specific condition of the patient (prenatal or emergency routine). Data collection and patient interaction activity form the basis for clinical work. The students need to integrate the scientific foundations of Medicine with clinical reasoning skills to guide their examination and information collection.

*Perform a complete and accurate physical examination of the pregnant woman in a logical and fluid sequence.

*Perform a clinically relevant and focused physical examination pertinent to the setting and purpose of the patient's visit (obstetric consultation).

*Identify, describe and document abnormal findings of the physical examination, clearly recording

Roles in this activity it in the medical file.

*Demonstrate patient-centered examination techniques that reflect respect for the patient's privacy, comfort and safety (for instance, explaining physical examination maneuvers, informing the patient about what is being done at each step, keeping her covered during the examination). *Demonstrate knowledge and perform the steps of the complete physical examination of the pregnant woman.

*Patient care

Relevant competence

domains for this activity

*Knowledge for the practice

* Interpersonal and communication skills

*Professionalism

( ) Should work only under direct supervision

Progression in this EPA ( ) Can work under indirect or remote supervision

( ) Can work without supervision (Milestones level 1)

\section{CH - EPA 3: perform the physical examination of the pregnant woman (obstetrics)}

When the student performs a complete physical examination of a woman who comes to the obstetrics appointment to perform the prenatal routine or due to a specific complaint:

- Is the student able to perform a complete and accurate physical examination of the woman in a logical and fluid sequence? (Follows the examination in the axial axis, from top to bottom, examining head, neck, upper limbs, pulmonary and cardiac auscultation, breasts, pregnant abdomen, groin, lower limbs, external and internal genitalia.)

- Does the student perform a clinically relevant and focused physical examination pertinent to the setting and purpose of the patient's visit? (Obstetric consultation.)
- Is the student able to effectively communicate with the patient, families and the public, as appropriate, across a wide range of socioeconomic and cultural backgrounds?

- Does the student identify, describe and document abnormal findings from the physical examination, clearly recording them in the medical file?

- Does the student demonstrate patient-centered examination techniques that reflect respect for the patient's privacy, comfort and safety? (By explaining the physical examination maneuvers, letting the patient know what they are doing at each step, keeping her covered during the examination.)

- Does the student demonstrate knowledge and perform the steps of the basic obstetric physical examination? (Uterine height measurement, fetal heart rate auscultation, Leopold maneuvers, vaginal touch.) 
Frame 2. EPA 4 - PATIENT CARE IN THE INTRAPARTUM PERIOD.

EPA 4 Student: Evaluator: Date:

The student must demonstrate basic knowledge of routine and uncomplicated intrapartum obstetric care, including the vaginal delivery conduct. Provide intrapartum obstetric care for Activity description women with uncomplicated pregnancies (identify fetal position, monitor fetal heart rate and uterine dynamics). Differentiate between normal and abnormal labor. Recognizes intrapartum complications (chorioamnionitis, shoulder dystocia).

*Identify the start of labor.

*Conduct the vaginal labor by auscultating the fetal heartbeat, identifying fetal position, assessing uterine dynamics and cervical dilation through vaginal touch.

${ }^{*}$ Correctly fill in the partograph and interpret it.

Roles in this activity $\quad{ }^{*}$ Correctly indicate and interpret the cardiotocography.

*Differentiate eutocic birth from dystocic birth.

*Perform the eutocic birth.

*Provide immediate postpartum care.

* Recognize an urgent/emergency situation and be able to communicate with the team to request support.

*Patient care

*Knowledge for the practice

* Interpersonal and communication skills

Relevant competence $\quad$ *Interpersonal and communication

domains for this activity * * $\quad$ Learning and improvement based on the practice

*Professionalism

* Systems-based practice

Progression in this EPA

() Should work only under direct supervision

() Can work under indirect or remote supervision

() Can work without supervision (Milestones level 1)

\section{CH - EPA 4: patient care during the intrapartum period}

When the student is attending to a patient in labor:

- Does the student identify the onset of labor? (Can tell the difference between labor and false labor.)

- Does the student perform a normal eutocic labor by auscultating the fetal heartbeat, identifying fetal position, assessing uterine dynamics and cervical dilation through the vaginal touch?

- Is the student able to correctly fill in the partograph and interpret it? (Identifies suspected abnormalities following labor upon the interpretation of the partograph.)

- Does the student correctly indicate and interpret the cardiotocography?

- Does the student differentiate eutocic birth from dystocic birth?
- Is the student capable of performing a eutocic birth, making all the necessary maneuvers, communicating with the pediatric team and other healthcare professionals?

- Is the student capable of providing immediate postpartum care? (Performs the placental discharge correctly, review the trajectory and perineum, contain small hemorrhages, identifying possible abnormalities.)

- Does the student recognize an urgent/emergency situation, being able to promptly communicate with the team to request support? (Manages the team by delegating assignments for quick resolution of complications.) 
Frame 3. EPA 9 - PRINCIPLES OF GYNECOLOGICAL SURGERY AND PERIOPERATIVE CARE.

\begin{tabular}{|c|c|c|}
\hline EPA 9 & Evaluator: & Date: \\
\hline Activity description & \multicolumn{2}{|c|}{$\begin{array}{l}\text { The student must demonstrate knowledge of basic pelvic and abdominal anatomy, and knowledge } \\
\text { of basic surgical principles, including the use of universal precautions and aseptic techniques. They } \\
\text { must demonstrate basic surgical skills, including making and removing simple sutures. }\end{array}$} \\
\hline Roles in this activity & $\begin{array}{l}\text { *Demonstrate professionalism and adequate behavi } \\
\text { * Adequately communicate with the surgical team. } \\
\text { *Know the basic anatomy of the region. } \\
\text { *Know how to adequately perform surgical scrub an } \\
\text { *Know how to correctly position the patient for the } t \\
\text { *Work effectively as a surgical assistant. } \\
\text { *Know the instruments and surgical suture threads. }\end{array}$ & ment. \\
\hline $\begin{array}{l}\text { Relevant competence } \\
\text { domains for this activity }\end{array}$ & $\begin{array}{l}\text { *Patient care } \\
\text { *Knowledge for the practice } \\
\text { *Interpersonal and communication skills } \\
\text { *Personal and professional development } \\
\text { * Practice-based learning and improvement } \\
\text { *Interprofessional collaboration } \\
\text { *Professionalism } \\
\text { *Systems-based practice }\end{array}$ & \\
\hline Progression in this EPA & $\begin{array}{l}\text { () Should work only under direct supervision } \\
\text { () Can work under indirect or remote supervision } \\
\text { () Can work without supervision (Milestones level 1) }\end{array}$ & \\
\hline
\end{tabular}

\section{CH - EPA 9: principles of gynecological surgery and perioperative care \\ When the student will participate in gynecological surgery:}

- Does the student demonstrate professionalism and appropriate behavior in the surgical environment?

- Does the student perform basic handwashing steps and know how to scrub and gown correctly?

- Is the student familiar with universal precautions and techniques for antisepsis, asepsis and sterilization?

- Is the student able to adequately communicate with the surgical team and assistants?

- Does the student demonstrate knowledge of basic pelvic and abdominal anatomy, correctly naming structures when requested?

- Does the student know how to correctly position the patient on the operating table according to the procedure to be performed?

- Does the student know the basic surgical instruments and types of suture threads?

- Is the student able to perform and remove simple sutures?

\section{DISCUSSION}

The medical course graduate must be at level 1 of the Milestones Project, demonstrating that they have the minimum knowledge required to work in the area of gynecology and obstetrics. Therefore, it is expected that, on the first day after graduating from medical school, the professional will be able to exercise the minimum and necessary requirements in gynecology and obstetrics to provide adequate care for women and pregnant women. Then, this professional should be able to perform these minimum requirements without supervision.

The 2014 National Curriculum Guidelines for the medical course in Brazil consolidated the medical graduate's desired profile based on the general, humanistic, critical, reflective and ethical training, allowing graduates to work at different levels of health care. For that purpose, it establishes the need for articulation between knowledge, skills and attitudes for the future professional practice ${ }^{16}$. The EPAs can also meet this context during undergraduate school, as they make it possible to both teach and verify whether the student is competent to perform a certain task that requires them to demonstrate integration between the knowledge, skill and necessary attitude for such.

Groups in other medical and nursing specialties in Brazil study the use of EPAs during graduation. In this work, we bring the novelty of using EPAs with checklists for teaching and evaluating the skills acquired in the area of gynecology and obstetrics during medical undergraduate school.

When the evaluator marks the first two options in the field "Progression in this EPA", the student cannot yet be "entrusted" with a certain task for them to perform it without supervision. This requires the need to repeat this EPA as many times as necessary until the student receives the assessment stating that they "Can work without supervision". When the student has reached the level of progression in the EPA performance, the evaluator considers them to be "reliable" to perform the described tasks and this is what is expected of the 
student at the end of undergraduate school. This is also what is expected on the first day of medical residency, that is, the graduate is aligned with level 1 of the "Milestone Project".

The EPA model thus applied demonstrates that the student is capable of performing tasks without supervision when they reach the end of undergraduate school, which is what is expected of them when graduating as a physician. The student can repeat the EPA as many times as necessary during the medical course, can observe their progress when learning the skills proposed in that EPA, and correct any failures and deviations while still under supervision. This provides them greater technical skills and dexterity in carrying out the practical procedures, in addition to developing postures and attitudes when solving each proposed topic. These possibilities, however, face criticism related to the effectiveness and viability of competence-based medical education ${ }^{14,15}$. The EPA model makes it possible to learn skills, as it makes it easier to observe the weaknesses in medical training and correct them before the future professional reaches the job market or medical residency. It also provides the student with a view of what needs to be improved in their learning.

The checklist with a detailed description of what needs to be achieved during the performance of each task can be completed based on the observation and monitoring of a person (resident of gynecology and obstetrics or a monitor) with more knowledge in the area than the student who performs the EPA, thus not implying an increase in expenses for its implementation and the need to hire several teachers for this purpose. However, the student must also pass the final evaluation of a teacher. It is important that the student be evaluated by teachers from the area at least a few times during undergraduate school.

Building a practical curriculum using EPAs can be understood as a "Task-based instructional strategy". Following five instructional principles: focus on the task, activation, demonstration, application, integration ${ }^{13}$. For educational purposes, it is not enough to identify EPAs just as a simple list of tasks or titles. Most task formulations are open to multiple interpretations. To allow for an assignment decision, there must be specifications. To illustrate this, if the EPA is "Perform anamnesis focused on gynecology and obstetrics" (EPA 1), the assignment decision should include specifications and limitations. For example, for medical students, high-risk patients who need urgent care are inadequate. Likewise, the final-year student can examine and evaluate a patient with a known condition, conduct additional diagnostic tests (EPA 7) and perform the necessary work, which must be completed under the supervision of a medical staff member. Moreover, the matrix approach to using EPAs requires specifying which competences must be present before participants can be entrusted to work unsupervised or with only indirect supervision.

An evaluation plan is needed to guide undergraduate students in their preparation for assignment decisions ${ }^{13}$.

EPAs can be beneficial for undergraduate students. These are focused on the continuity and progression of student development, on the generalization and applicability through the continuity of the underlying principles of EPAs, and the recognition and quality assurance of student work in the clinical workplace ${ }^{8}$. The end of medical school can be seen as the completion of a specific developmental period with its own expectations of competence.

It is necessary to demonstrate to the public and the academic community that competence-based medical education is centered on a solid educational theory and contributes not only to the professional training of physicians who incorporate work habits to improve patient and population care, but also contributes to care systems ${ }^{17}$.

\section{CONCLUSION}

The use of EPAs during undergraduate school adds value to competence-based medical education, as it facilitates and operationalizes the learning, development and observation of the acquisition of knowledge, skills and attitudes required in the performance of each topic in gynecology and obstetrics, thus allowing the training of a competent professional. This innovative study for the teaching of gynecology and obstetrics in medical undergraduate provides a detailed description of the task to be performed, as well as a checklist for checking the items performed by the student, providing the evaluator with clarity as to what should be performed and evaluated, in a practical and fast way, without requiring educational institutions to spend extra time or expenses with the use of EPAs. Moreover, the EPAs and their respective checklists - always available to the student during undergraduate school - provide the opportunity for them to be repeated as many times as necessary for the learning and mastering of the requested functions, which the student can previously visualize in the checklist. This allows the student a self-assessment by identifying the need for training and further learning in a given subject or correction of failures and learning deviations, which is one of the biggest advantages of using EPAs during undergraduate.

Another advantage is that the same EPA can be included at different times during medical undergraduate school for the learning of gynecology and obstetrics. Some EPAs are included at the beginning of the course and remain until the end; others are included in more advanced years, according to the expected depth of learning. This "malleability" regarding 
the use of this model facilitates its inclusion both in traditional medical teaching and in those with active methodologies.

At the end of the medical course, the ability to perform all the EPAs suggested throughout the medical undergraduate identifies a competent graduate in gynecology and obstetrics, regarding the general practitioner. However, we need to carry out more studies to assess the applicability of EPAs in medical undergraduate, which is already being done in a pilot project that will bring us future data.

\section{AUTHORS' CONTRIBUTION}

The authors declare that they all contributed equally to the work.

\section{CONFLICTS OF INTEREST}

The authors declare no conflicts of interest.

\section{SOURCES OF FUNDING}

The authors declare no sources of funding.

\section{REFERENCES}

1. Ten Cate O. Guia atualizado sobre Atividades Profissionais Confiáveis (APCs). Rev Bras Educ Med. 2019;43(1 Supl.1):721-30.

2. Aguiar AC, Ribeiro EC. Conceito e avaliação de habilidades e competência na educação médica: percepções atuais dos especialistas. Rev Bras Educ Med. 2010;34(3):371-8.

3. Passini Júnior R. Ensino da cirurgia ginecológica nos programas de residência médica do Brasil. Rev Bras Ginecol Obstet. 2007;29(2):61-6.

4. Ten Cate O. Nuts and bolts of entrustable professional activities. J Grad Med Educ. 2013;5(1):157-8.

5. ten Cate O. Entrustability of professional activities and competency-based training. Med Educ. 2005;39(12):1176-7.
6. ten Cate O, Scheele F. Viewpoint: Competency-based postgraduate training: can we bridge the gap between theory and clinical practice? Acad Med. 2007;82(6):542-7.

7. Mulder $\mathrm{H}$, ten Cate $\mathrm{O}$, Daalder R, Berkvens J. Building a competency-based workplace curriculum around entrustable professional activities: the case of physician assistant training. Med Teach. 2010;32:453-9.

8. Chen HC, O'Sullivan P, Teherani A, Fogh S, Kobashi B, Ten Cate O. Sequencing learning experiences to engage different level learners in the workplace: an interview study with excellent clinical teachers. Med Teach. 2015;37(12):1090-7.

9. Pangaro $L$, Ten Cate O. Frameworks for learner assessment in medicine. AMEE guide n78. Med Teach. 2013;35:1197-210.

10. Gentile P, Bencini R. Construindo competências: entrevista com Philippe Perrenoud, Universidade de Genebra. Nova Escola. 2000. [access in 7 mar 2017]. Available from: http://www.unige.ch/fapse/SSE/teachers/ perrenoud/php_main/php_2000/2000_3 1.html.

11. Association of American Medical Colleges. Core Entrustable Professional Activities for Entering Residency: Curriculum Developer's Guide. 2014. [access in 18 jan 2017]. Available from: https://store.aamc.org/ downloadable/download/sample/sample_id/63/.

12. The Obstetrics and Gynecology Milestone Project. J Grad Med Educ. 2014;6(1 suppl):129-43. [access in $21 \mathrm{dec} 2016$ ]. Available from: https://doi.org/10.4300/JGME-06-01s1-07.

13. ten Cate $\mathrm{O}$, Chen HC, Hoff RG, Peters H, Bok H, Van Der Schaaf M. Curriculum development for the workplace using entrustable professional activities (EPAs). AMEE Guide n99. Med Teach. 2015:1-20.

14. Talbot M. Monkey see, monkey do: a critique of the competency model in graduate medical education. Med Educ. 2004;38(6):587-92.

15. Whitehead CR, Kuper A. Faith-based medical education. Adv in Health Sci Educ. 2017;22(1):1-3.

16. Brasil. Ministério da Educação. Conselho Nacional de Educação. Resolução CNE/CES n 3, de 20 de jun. de 2014. Diretrizes Curriculares Nacionais do Curso de Graduação em Medicina e dá outras providências. Diário Oficial da República Federativa do Brasil, Brasília, 23 jun. de 2014; (Seção 1):8-11.

17. Carracio CL, Englander R, Van Melle E, Ten Cate O, Lockyer J, Chan MK, et al. Advancing competency-based medical education: a charter for clinicianeducators. Acad Med. 2016;91(5):645-9. 